\title{
AMCoR
}

Asahikawa Medical College Repository http://amcor.asahikawa-med.ac.jp/

Vector-Borne and Zoonotic Diseases (2004) 4(2):95-107.

Cysticercosis/taeniasis in Asia and the Pacific

Ito, Akira ; Wandra, Toni ; Yamasaki, Hiroshi ; Nakao, Minoru ; Sako, Yasuhito ; Nakaya, Kazuhiro ; Margono, Sri S. ; Suroso, Thomas ; Gauci, Charles ; Lightowlers ; Marshall W. 


\title{
Review
}

\section{Cysticercosis/Taeniasis in Asia and the Pacific}

\author{
AKIRA ITO, ${ }^{1}$ TONI WANDRA, ${ }^{1,2}$ HIROSHI YAMASAKI, ${ }^{1}$ MINORU NAKAO, ${ }^{1}$ \\ YASUHITO SAKO, ${ }^{1}$ KAZUHIRO NAKAYA, ${ }^{3}$ SRI S. MARGONO, ${ }^{4}$ THOMAS SUROSO, ${ }^{2}$ \\ CHARLES GAUCI, ${ }^{5}$ and MARSHALL W. LIGHTOWLERS ${ }^{5}$
}

\begin{abstract}
Three taeniid tapeworms infect humans in Asia and the Pacific: Taenia solim, Taenia saginata, and Taenia asiat$i c a$. Although there is continuing debate about the definition of a new species, phylogenetic analyses of these parasites have provided multiple lines of evidence that $T$. asiatica is an independent species and the sister species of $T$. saginata. Here we review briefly the morphology, pathology, molecular biology, distribution and control options of taeniasis/cysticercosis in Asia and the Pacific and comment on the potential role which dogs may play in the transmission of $T$. solium. Special attention is focused on Indonesia: taeniasis caused by $T$. asiatica in North Sumatra, taeniasis/cysticercosis of $T$. solium and taeniasis of $T$. saginata in Bali, and taeniasis/cysticercosis of $T$. solium in Papua (formerly Irian Jaya). Issues relating to the spread of taeniasis/cysticercosis caused by T. solium in Papua New Guinea are highlighted, since serological evidence suggests that cysticercosis occurs among the local residents. The use of modern techniques for detection of taeniasis in humans and cysticercosis in humans, pigs and dogs, with the possible adoption of new control measures will provide a better understanding of the epidemiology of taeniasis/cysticercosis in Asia and the Pacific and lead to improved control of zoonotic and simultaneously meat-borne disease transmission. Key Words: Taenia solium-T. saginata-T. asiatica-CysticercosisTaeniasis-Asia and the Pacific-Indonesia-Papua New Guinea-Emerging and re-emerging zoonotic disease-Immunodiagnosis-Molecular diagnosis-Vaccine. Vector-Borne Zoonotic Dis. 4, 95-107.
\end{abstract}

\section{INTRODUCTION}

I NFECTIONS IN HUMANS with the adult tapeworms of Taenia spp. (taeniasis) and in humans and animals with the metacestode stages of these parasites (cysticercosis) are recognized to occur in countries in the Asia-Pacific region (Ito 1992, Simanjuntak et al. 1997, Rajshekhar et al. 2003). However, their epidemiology in Asia has not been the subject of substantial scientific investigation. Relatively recently our understanding of this disease complex has im- proved following the recognition that, in addition to the pork tapeworm, Taenia solium and the beef tapeworm, Taenia saginata, a third Taenia species infects humans in Asia. Several decades ago it was recognized that taeniid cestodes expelled from local people in some areas of Asia appeared to be T. saginata (so called Asian Taenia), although the persons harboring the parasites ate pork but not beef (Kosin et al. 1972). The unique life cycle of Asian Taenia was demonstrated experimentally by Fan (1988) in Taiwan. In contrast to $T$. saginata, pigs act as

\footnotetext{
${ }^{1}$ Department of Parasitology, Asahikawa Medical College, Asahikawa, Japan.

${ }^{2}$ Communicable Disease Control and Environmental Health, Ministry of Health, Indonesia, Jakarta, Indonesia.

${ }^{3}$ Animal Laboratory for Medical Research, Asahikawa Medical College, Asahikawa, Japan.

${ }^{4}$ Department of Parasitology, Faculty of Medicine, University of Indonesia, Jakarta, Indonesia.

${ }^{5}$ Molecular Parasitology Laboratory, University of Melbourne, Victoria, Australia.
} 
the intermediate host where infective metacestodes develop in the liver. The metacestodes in pigs have only rudimentary or vestigial hooks, but adult tapeworms lack rostellar armature and in this regard are similar to T. saginata. Eom and Rim (1993) suggested this parasite to be a new species, Taenia asiatica, and provided the first full description with a justification for recognizing and naming the species. It is now clear that there are two sister species in Asia, T. saginata from beef and $T$. asiatica from viscera of pigs (reviewed by Fan 1988, Fan and Chung 1998, Eom and Rim 2001, Hoberg 2002, Pawlowski 2002, Ito et al. 2003a, 2003b). According to the criteria for the speciation of discrete biological entities, $T$. asiatica is expected to be an independent species and is the sister species of T. saginata (Hoberg 2002).

This brief review considers the present situation concerning human Taenia infections in Asia and the Pacific with special emphasis on the epidemiology of infections in Indonesia and Papua New Guinea (PNG). Advances in technology for diagnosis and cysticercosis control are also discussed.

\section{Taenia species infecting humans in Asia} and the Pacific

It is clear that human taeniasis and cysticercosis are present in Asia and the Asian-Pacific region. T. solium occurs in the majority of Asian countries, including China, India, Indonesia, Thailand, Laos, Cambodia, Nepal, Philippines, Myanmar, Vietnam, and Korea (reviewed by Singh et al. 2002), where local people consume pork. In PNG, serological studies have suggested that $T$. solium infections can be associated with the movement of Papuan refugees (Fritzsche et al. 1990, Wandra et al. 2003).

Pork is a staple part of the diet in China, especially in rural villages and $T$. solium cysticercosis is a serious public health issue in this country (Singh et al. 2002, Ito et al. 2003b). In southeast Asia, including the southern part of China and northern part of Vietnam, it is common for rural people to live in houses where pigs, dogs, and other animals are housed under the floors. Indeed, the Chinese character meaning "house" shows pigs kept under the roof (under the floor) and reflects the tradi- tional way of life. Such a situation predisposes these communities to transmission of $T$. solium from human to pigs.

The situation with regard to taeniasis in humans in Asia should be re-evaluated based on features such as mitochondrial DNA (mtDNA) sequences that are able to differentiate $T$. saginata and T. asiatica (Zarlenga et al. 1991, Bowles and McManus 1994, Eom and Rim 2001, Nakao et al. 2002, Yamasaki et al. 2002, 2004). It is therefore necessary to engage in new and broadbased surveys across this region. Analyses using mtDNA have revealed that $T$. asiatica is distributed in Taiwan, China, South Korea, Indonesia and Vietnam (Eom et al. 2002, Willingham et al. 2003, Yamasaki et al. 2004). It is likely that it also exists in Thailand (Fan et al. 1990), the Philippines (Fan et al. 1992, Bowles and McManus 1994), and Malaysia (Bowles and McManus 1994).

\section{Biology of the three human Taenia species}

The three human taeniid species and their development in intermediate host animals are summarized in Table 1 (Ito et al. 2001, 2003a, Pawlowski 2002). The critical difference between T. asiatica and T. saginata is the preferred intermediate host of each species. T. asiatica utilizes the pig whereas $T$. saginata predominantly infects cattle. The cysticercus of $T$. asiatica is typically small, being about $2 \mathrm{~mm}$ in diameter, and occurs predominantly in the liver of pigs while $T$. saginata cysticerci may develop up to $10 \mathrm{~mm}$ in diameter and occur predominantly in the musculature of cattle. Figure 1 shows mature cysticerci of $T$. saginata and $T$. asiatica that developed in severe combined immunodeficiency (scid) mice, particularly in non-obese diabetic scid (NOD/Shi-scid) mice (Ito et al. 2001). In vitro hatched oncospheres of all these human taeniid species can develop into fully mature cysticerci in NOD/Shi-scid mice (Ito et al. 1997, 2001, reviewed by Ito and Ito 1998, Ito et al. 2003a). The potential for such development of cysticerci in model hosts provides an opportunity to obtain large quantities of parasite material for research and diagnostic purposes, particularly into T. asiatica, which is relatively difficult to obtain.

Based on molecular phylogenetic analysis, it has been revealed that $T$. asiatica is closely re- 
Table 1. Taenia Species Infecting Humans in the Asia-Pacific Region

\begin{tabular}{lccc}
\hline Species & Definitive host & Principal intermediate host(s) & Size of metacestode $(\mathrm{mm})$ \\
\hline Taenia solium $^{\mathrm{a}}$ & Human & Pig (human) & $5-8 \times 3-6$ \\
Taenia asiatica & Human & Pig & $\left(5-8 \times 3-6^{\mathrm{c}}\right)$ \\
& & $2 \times 2$ \\
Taenia saginata & Human & Cattle & $\left(7-10 \times 4-6^{\mathrm{c}}\right)$ \\
& & & $7-10 \times 4-6$ \\
& & $\left(7-10 \times 4-6^{c}\right)$ \\
\hline
\end{tabular}

aThe number of hooks of the metacestode of T. solium grown in NOD/Shi-scid mouse is highly variable from 0 to 32 (Margono et al. 2003).

bAlthough humans are commonly infected with the metacestodes, these infections are not involved in subsequent transmission of the parasite (Hoberg et al. 2001).

'The size of metacestodes grown in NOD/Shi-scid mouse 150 days after inoculation of in vitro hatched oncospheres (Ito et al. 2001; unpublished).

lated to T. saginata with some distinct but minor differences in DNA sequence (Zarlenga et al. 1991, Bowles and McManus 1994, Hoberg et al. 2000, Eom et al. 2002, Ito et al. 2002b). The debate on whether this porcine parasite should be classified as a new species ( $T$. asiatica) or a subspecies ( $T$. saginata asiatica) has been the topic of considerable debate over the past decade (Fan et al. 1995, reviewed by Ito et al. 2003a, 2003b, Ito and Craig 2003). However, the
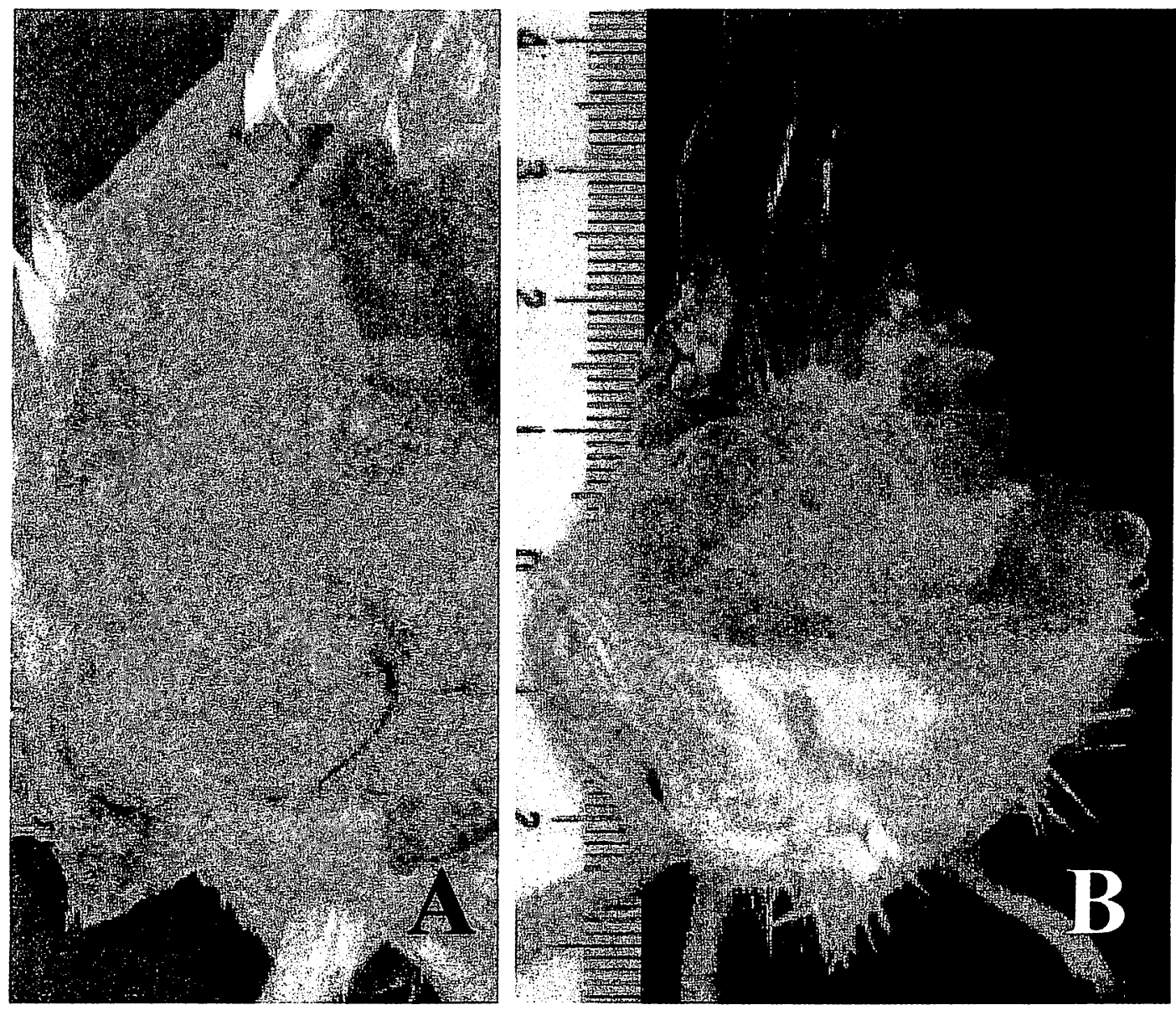

FIG. 1. Cysts of Taenia saginata (A) and Taenia asiatica (B) in NOD/Shi-scid mice 5 months after injection of in vitro hatched oncospheres. 
extent of the evidence for $T$. asiatica being an independent species-level taxon is difficult to refute without any evidence of hybrids (Eom et al. 2002, Hoberg 2002). Available evidence suggests that $T$. asiatica does not cause cysticercosis in humans, as is also the situation with its sister-species, $T$. saginata (Ito et al. 2003a). The physiological basis for the differentiation between $T$. saginata/T. asiatica and $T$. solium, in this respect, remains unknown.

To date no evidence has been found to suggest the existence of genetic hybridization between $T$. saginata and T. asiatica in China where the two species occur sympatrically (Eom et al. 2002, Yamasaki et al. 2004), although the data available appear not to be sufficient as conclusive evidence. This may be expected to provide further evidence for assigning $T$. asiatica as a new species. However, as distinct from freeliving animals and plants, parasites such as cestodes are often isolated as individuals within their human host with limited probability of simultaneous exposure to dual infections (Ito and Craig 2003, Ito et al. 2003a, 2003c, McCoy 2003, Meeûs et al. 2003). This is largely affected by traditional, cultural and religious factors. Therefore, as discussed previously (Ito et al. $2003 b)$, it would be interesting to determine if these two species had the capacity to form hybrids if given the opportunity to co-exist in a single host. There is a report describing detection of out-cross of a related taeniid species, Echinococcus multilocularis (Nakao et al. 2003) and between sister species of Schistosoma mansoni and S. rodhaini (Morgan et al. 2003).

\section{Techniques available for identification and} diagnosis of taeniasis and cysticercosis caused by T. solium, T. saginata, and T. asiatica

The various techniques that are available for differentiation of the different species of Taenia in humans are summarized in Table 2 (Ito and Craig 2003). When proglottids are obtained from patients, preliminary differentiation of the parasite species can be made by observation of segment morphology. Where possible, it is also valuable to support morphological observations by analysis of mtDNA (Bowles and McManus 1994). Such DNA analysis, using PCR, can be undertaken using material ob- tained from proglottids, eggs or metacestode samples. In addition, the presence of taeniid DNA in fecal samples can be confirmed by copro-DNA analysis (González et al. 2000, Yamasaki et al. 2004) and a copro-antigen test can be used to detect taeniasis (Allan et al. 1990, 1996, 2003). Serological methods to detect specific antibodies in taeniasis (Wilkins et al. 1999, Nakao et al. unpublished) and cysticercosis (Tsang et al. 1989, Ito et al. 1998, Yang et al. 1998, Chung et al. 1999, Del Brutto et al. 2001) are also available for use with human serum samples as well as for animal intermediate hosts (Tsang et al. 1991, Ito et al. 1999, 2002a, Subahar et al. 2001, Sato et al. 2003). Alternatively, detection of circulating antigens is also available (Harrison et al. 1989, Brandt et al. 1992, Garcia et al. 2000, Nguekam et al. 2003, Ito and Craig 2004).

The situation with regard to the availability and type of serological assays for diagnosis of cysticercosis is changing. Currently, specific serology for $T$. solium cysticercosis is available from CDC, Atlanta (Tsang et al. 1989) and from Asahikawa Medical College (AMC) (Ito et al. 1998; reviewed by Ito and Craig 2003). The immunoblot developed at CDC utilizing a fraction of cysticercus glycoproteins has been recognized as the "gold standard" for serology of cysticercosis, however the same antigenic preparation was not effective when used in a simpler serological technique such as ELISA. More recently, glycoproteins purified using preparative isoelectric focusing at AMC have been found to contain very few contaminants and serological results in immunoblot and ELISA were very similar, allowing this preparation to be used for specific diagnosis of cysticercosis in ELISA (Ito et al. 1998, 1999, Sato et al. 2003). The biochemical and molecular characteristics of the diagnostic glycoproteins are being determined (Chung et al. 1999, 2002, Sako et al. 2000, Greene et al. 2000, Hancock et al. 2003) and it appears likely that defined recombinant antigens may eventually replace the glycoproteins derived from cysticerci that are currently being used (Hancock et al. 2004).

Little genetic variation has been detected among isolates of $T$. asiatica and considerably less than that observed for $T$. saginata (Yamasaki et al. unpublished). Molecular evidence 
Table 2. Immunological and Molecular Techniques Available FOR DiAGNOSIS/IDENTIFICATION OF TAENIASIS/CYSTICERCOSIS

Technique

References

Immunological techniques

Detection of antibodies for cysticercosis in

humans, pigs and dogs

Detection of circulating antigens for cysticercosis in humans and pigs

Serology for taeniasis in humans

Copro-antigen test for detection of taeniasis in humans

Molecular techniques

DNA analysis for identification of taeniid species

Mitochondrial DNA analysis for identification of taeniid species and two genotypes of $T$. solium worldwide

Copro-DNA test
Gottstein et al. 1986; Parkhouse and Harrison 1987; Tsang et al. 1989, 1991; Yang et al. 1998; Ito et al 1998, 1999, 2002a; Chung et al. 1999; Sako et al. 2000; Wandra et al. 2000, 2003; Subahar et al. 2001; Del Brutto et al. 2001; Hancock et al. 2003; Sato et al. 2003

Harrison et al. 1989; Brandt et al. 1992; Garcia et al. 2000; Nguekam et al. 2003

Wilkins et al. 1999; Nakao et al. unpublished

Allan et al. 1990, 1996, 2003

Zarlenga et al. 1991; Bowles and McManus 1994; Eom and Rim 2001; Nakao et al. 2000, 2002; Yamasaki et al. 2002, 2004

Okamoto et al. 2001; Nakao et al. 2002; Yamasaki et al. 2002, 2004

González et al. 2000, 2002a,b; Yamasaki et al. 2004 suggests that $T$. solium emerged several million years ago in Africa (Hoberg et al. 2001) and has differentiated into two genotypes: Asian and American/African (Okamoto et al. 2001) over a period of approximately one million years (Nakao et al. 2002; reviewed by Ito et al. 2002b, $2003 \mathrm{~b})$. While there are clear genetic differences between these two $T$. solium genotypes, no definitive evidence exists at this stage for there being other biological differences between Asian and American/African parasites.

\section{Distribution of the three human taeniid species in Indonesia}

In Indonesia T. solium is known to occur in Bali and in Papua (Irian Jaya) (Sutisna et al. 1999, Wandra et al. 2000, 2003, Subahar et al. 2001, Ito et al. 2002a, Margono et al. 2003, reviewed by Simanjuntak et al. 1997, Singh et al. 2002) while T. asiatica exists in the Batak ethnic communities in Sumatra, especially in Samosir Island in Lake Toba, North Sumatra (Kosin et al. 1972). T. saginata also occurs in Bali (Simanjuntak et al. 1977, Sutisna et al. 1999). T. solium taeniasis in Bali and T. asiatica taeniasis in Samosir Island are now not easy to detect because local customs have changed and people are tending to eat well-cooked pork especially on Samosir Island; also pigs are increasingly being grown with no direct contact with human feces particularly in Bali. However, the prevalence of $T$. saginata taeniasis is increasing in Bali where uncooked beef is now more commonly eaten by local people as the economic situation in Bali has improved. In many Asian countries people often eat pork when their economic situation is poor but when it improves, many people move to eating beef. In Bali, although the majority of the local population is Hindu (non-strict Hindu), the eating of uncooked minced beef with vegetable and coconuts is increasing in popularity and replacing uncooked minced pork with fresh pig blood, known as "LAWAR." Following a field survey in December 2002 in Bali, 29 local people from 125 villagers were confirmed to have taeniid cestodes. A total of 32 tapeworms were expelled after antihelmintic treatment and confirmed to be $T$. saginata by morphology and mtDNA analysis (Wandra et al. unpublished).

Human cases of $T$. solium cysticercosis continue to occur in Bali, but it is very difficult to detect $T$. solium taeniasis in Bali nowadays. There is no definitive evidence for the presence of $T$. asiatica in Bali, although 146 of 638 pigs (22.9\%) at a slaughter house in Bali in 1998 were found to have cysts in the liver (Sutisna et al. unpublished). 
Taeniasis/cysticercosis of Taenia solium in Papua (Irian Jaya)

New Guinea Island is divided politically into two countries. The western part was governed by the Dutch but more recently has been incorporated into Indonesia (from 1969) and called Irian Jaya until becoming known since 2000 as Papua. The eastern part, PNG was previously governed by Australia and is now an independent country. $T$. solium is the only taeniid cestode found in humans in Papua. An increasing flow of refugees from Papua entering PNG has been raising concerns with the PNG government that these people may carry infectious diseases and $T$. solium particularly, into PNG (Fritzsche et al. 1990, McManus 1995, Flew 1999, Wandra et al. 2003, Thompson et al. 2003, Ito et al. 2003a). A report which investigated the distribution of $T$. solium taeniasis/ cysticercosis in Papua and PNG has been published recently (Wandra et al. 2003). T. solium cysticercosis has been confirmed from Paniai, Jayawijaya and Manokwari Districts in Papua. Table 3 summarizes the results of serological investigations carried out on samples from 96 local people in Jayawijaya District, Papua. As there was no hospital where computed tomography (CT) or magnetic resonance imaging (MRI) could be used to confirm cysticercosis infection in individuals, it was only possible to check for subcutaneous nodules, known locally as "Biji-Biji," and positive serology using an immunoassay with specific glycoprotein antigens (Ito et al. 1998, Wandra et al. 2003, Margono et al. 2003). As summarized in Table 3, it was clear that the majority of the local people with a history of epileptic seizures and subcutaneous nodules were serologically positive for cysticercosis. Figure 2 illustrates the results of cysticercosis ELISA carried out on samples from 96 local people from Jayawijaya District. Subcutaneous nodules, removed from some individuals were analyzed morphologically and by mtDNA analysis and were confirmed to be the T. solium Asian genotype (Wandra et al. 2003). It was concluded that more than $80 \%$ of local people over 18 years old who had history of epileptic seizures and subcutaneous nodules from Jayawijaya were confirmed as having cysticercosis based upon serological and mtDNA analysis (Table 3). Approximately $30 \%$ of asymptomatic healthy people were serologically identified as positive for cysticercosis although follow-up investigations with these people indicated that many did have detectable subcutaneous nodules. Clearly the simplest method which can give a good indication of cysticercosis in very remote areas is physical examination for detection of subcutaneous nodules (Wandra et al. 2003, Ito et al. 2003a).

In many areas of Papua, local people live with free-ranging pigs and dogs, and latrines are rarely used hence these animals have free access to human feces. Serological analysis of pigs from Jayawijaya District, Papua revealed approximately $70 \%$ to be seropositive (Subahar et al. 2001). Furthermore, $11.0 \%$ (7/64) of local dogs in Jayawijaya, Papua were found to be

Table 3. Serological Analysis of 96 local People in Jayawijaya District, PAPUA 1996 For Detection of SPECIFIC ANTIBOdy Responses AgAinst tHe GlyCOPROTEINS OF TAENIA SOLIUM CYSTICERCI

\begin{tabular}{|c|c|c|}
\hline Groups & No. of persons examined & $E L I S A(\% \mathrm{~d})$ \\
\hline $\mathrm{ES}^{\mathrm{a}}$ & 17 & $12(70.6)$ \\
\hline With SCN $\mathrm{S}^{\mathrm{b}}$ & 12 & $10(83.3)$ \\
\hline Without SCN & 5 & $2(40.0)$ \\
\hline $\mathrm{SCN}$ & 32 & $20(62.5)$ \\
\hline Subtotal & 49 & $32(65.3)$ \\
\hline $\mathrm{HP}$ at risk ${ }^{\mathrm{c}}$ & 47 & $14(29.8)$ \\
\hline Total & 96 & $46(47.9)$ \\
\hline
\end{tabular}

aWith history of epileptic seizures.

bWith subcutaneous nodules.

'Healthy people at risk.

dPercentage of no. of seropositive persons/no. of examined persons (Fig. 2).

Original data from Wandra et al. 2003. 


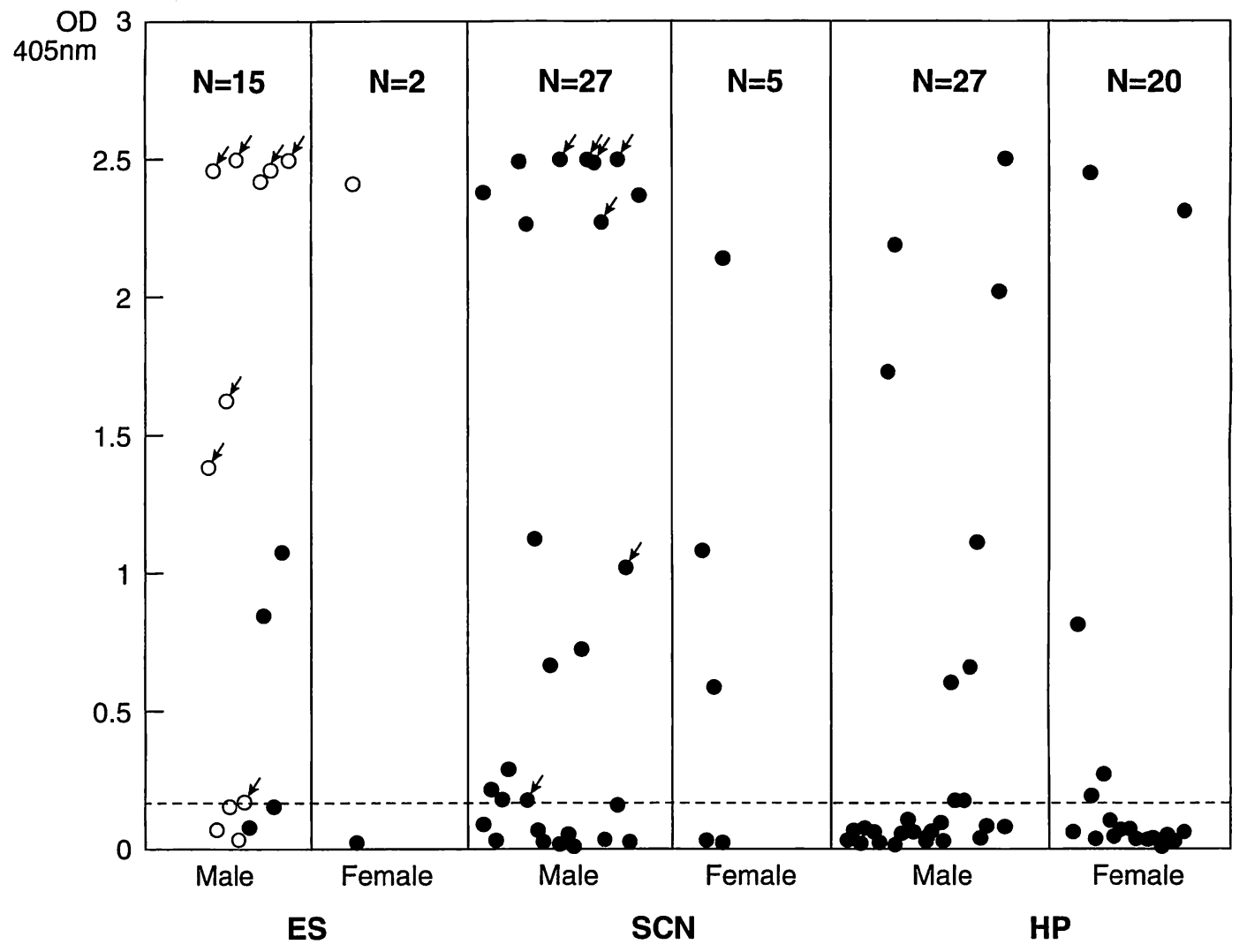

FIG. 2. ELISA results of 96 local people from Jayawijaya District in Papua, Indonesia 1996. ES, SCN, and HP groups represent individuals with a history of epileptic seizures, individuals with subcutaneous nodules and healthy individuals at risk, respectively (Table 3) (original data from Wandra et al. 2003). Open circles represent individuals with both ES and SCN. Arrows show 14 persons from whom subcutaneous nodules were resected and confirmed to be viable $T$. solium cysticerci by either morphological or mitochondrial DNA analysis. There was no difference in antibody responses in local people of cysticercosis with or without history of epilepsy.

positive in serological assays for cysticercosis and were subsequently confirmed to harbor viable T. solium cysticerci (Ito et al. 2002b).

\section{Occurrence of $\mathrm{T}$. solium taeniasis/cysticercosis in PNG}

Investigations into the presence and distribution of T. solium from PNG are preliminary. Approximately 600 human serum samples from PNG have been tested for cysticercosis (Wandra et al. 2003, Ito et al. 2003a, Ito et al. unpublished). Approximately 3\% of them were found to be serologically positive for cysticercosis. One (29-year-old) woman whose spouse was a Papuan refugee showed an antibody response typical of cysticercosis and reported occasional headaches indicating possible neurocysticercosis. Other positive cases showed relatively weak responses and were possibly exposed to eggs of $T$. solium.

The first suspected cysticercosis case was reported from a Papuan refugee (Fritzsche et al. 1990) who was serologically positive for cysticercosis using an immunoblot method (Gottstein et al. 1986). The detection of cysticercosis in non-imported cases may be crucial to suggest that $T$. solium might have been established in PNG even prior to the arrival of Papuan refugees (McManus 1995, Flew 1999, Thompson et al. 2003). Therefore, field surveys in local people and pigs to detect cysticercosis, by serology and post-mortem observation of cysts in pigs are matters of priority in studies investigating the distribution of $T$. solium in PNG and East Timor and other neighbor areas where the majority is Christian and eat pork (Ito et al. 2003a). 
Possible role for dogs in the transmission of $\mathrm{T}$. solium cysticercosis

Pigs are the principal intermediate host for $T$. solium, however numerous other species have been described as suitable intermediate hosts. In addition to pigs and humans as intermediate hosts of T. solium, Abuladze (1964) cited as hosts a variety of species of boar, pig and monkey as well as the dog, rabbit, hare, camel and bear. Many of these observations have relied on diagnoses based on parasitological features of the cysticerci, particularly the size and morphology of the rostellar hooks, and possibly include some cases of misidentification. However, there are numerous independent reports identifying cysticerci of $T$. solium in the domestic dog (Canis familiaris) from a variety of geographical sites (see literature cited by Abuladze 1964). More recently, experimental confirmation of the ability of $T$. solium to cause viable infections with cysticerci in the muscles of dogs was provided by Fan et al. (1994) using T. solium eggs from proglottids obtained from a patient in Hainan Province, China. As has been mentioned earlier, serological and necropsy examination of dogs in the Jayawijaya region of Papua have confirmed many to be infected with viable cysticerci of $T$. solium. Not only is there a large dog population in Indonesia (recently the Indonesian Ministry of Agriculture estimated the country's dog population to be approximately $1 / 16$ of the human population), but the consumption of dog meat by humans occurs frequently in Sumatra, Sulawesi, the Flores Islands, Java and Papua. The eating of dog meat is traditional and common in many other Asian countries, including Thailand, Vietnam, China, and Korea (see Hou 1983, Dissamarn and Indrakamhang 1985, Cui and Wang 2001). Furthermore, the eating of dog meat is known to occur in many non-Asian countries, including many parts of Africa, Latin America, and some European countries. Hence, the transmission of $T$. solium between dogs and humans could occur if the people were to eat undercooked meat from dogs infected with $T$. solium cysticerci. While this possibility has been recognized since the earliest descriptions of the presence of the larval parasite in dogs, the significance of this potential mode of transmission of T. solium to humans has not, to our knowledge, been the subject of specific investigation. This could be an important, previously underrecognized factor in understanding the epidemiology of $T$. solium transmission and may need to be given particular consideration in relation to future efforts to better understand the epidemiology of T. solium cysticercosis and taeniasis, particularly in Asia.

\section{Potential strategies for control of cysticercosis in Asia}

In the same way that improvements in sanitary conditions and public education which occurred over the past century in Europe have had a major impact of the transmission of taeniasis/cysticercosis, similar improvements in the standard of public hygiene and education are likely to reduce the impact of neurocysticercosis in Asian countries. Industrialization and intensification of pig-rearing practices could also be expected to lead to decreased potential for exposure of pigs to human feces and hence decreased transmission of $T$. solium. However, such changes are generally associated with increases in general living standards, and, for those communities in developing countries in which neurocysticercosis is a significant cause of human morbidity and mortality, other disease control measures are required in order to achieve disease control in the foreseeable future.

Effective anthelmintics are available to eliminate the adult tapeworm from Taenia carriers. However, while ever there exists a substantial reservoir of the parasites in pigs which can cause new cases of taeniasis, the potential remains for continued disease transmission. Theoretically, control could be obtained by sustained diagnosis and treatment of Taenia carriers, or by treatment of the whole population with anthelmintics sufficiently regularly so as to prevent the occurrence of any gravid tapeworms within the population. For T. solium, this would require treatment approximately every 3 months. It may be necessary to persist with such treatments while any infected pigs remain as a source of new infections in humans. Some success has been achieved in controlling $T$. solium through anthelmintic treatment of 
Taenia carriers, public education, or both (Sarti et al. 2000); however, no examples exist where such measures have led to the sustainable control of the parasite. The difficulty with such an approach in the developing world is in the cost and hence sustainability of the control measures for a sufficient length of time.

The recent discovery of a single anthelmintic treatment that can eliminate viable cysticerci from pigs provides an important potential new control measure to assist with $T$. solium control (Gonzáles et al. 1996, 2001). A regime whereby all pigs were treated before slaughter would remove the source of $T$. solium taeniasis in humans. While this measure has the potential to play a valuable role in control of $T$. solium, it remains to be seen whether it is adopted widely for parasite control or whether the organizational structure required to administer it effectively, especially where informal slaughter occurs, will limit this as a control measure.

Recent research results point to the development of a potentially powerful new control measure for $T$. solium based on prevention of parasite transmission through pigs by application of a vaccine. Several research groups are active in the area, and early results look very promising. Two DNA based vaccines have been described as inducing protection against challenge infection in pigs with $T$. solium (Cai et al. 2001, Wang et al. 2003). Using a different approach, Huerta et al. (2001) have undertaken a field trial in pigs using synthetic peptides. The sequences of these peptides were based on the amino acid sequences of antigens discovered in the mouse model parasite Taenia crassiceps. Pigs vaccinated with the peptides showed a reduction in the number of animals having very high levels of infection. A vaccine which was capable of achieving this effect on a reliable basis could have an impact on the probability of transmission of the parasite to humans and, indirectly, reducing the incidence of both human taeniasis and neurocysticercosis.

An alternative approach which is being taken to vaccine development is through the application of recombinant oncosphere antigens. This approach has been successful in developing practical vaccines that reliably provide $>95 \%$ protection against cysticercosis in sheep due to Taenia ovis and cattle due to T. sag- inata. These data have been reviewed recently elsewhere (Lightowlers et al. 2003). More recently, a similar approach has been adopted towards the development of a practical vaccine against $T$. solium infection in pigs. Oncosphere antigens have been cloned, characterized, and expressed, being the homologues of the $45 \mathrm{~W}$ antigen (Gauci et al. 2001) and the $18 \mathrm{~K}$ antigen (Gauci et al. 1998). Two independent trials have been completed in Mexico using these proteins (TSOL18 and TSOL45) as vaccines against experimental challenge infection with T. solium in pigs. In both trials, the TSOL18 antigen induced complete or near complete protection against the development of cysticerci following the challenge infection (Flisser et al. unpublished). Much further development work is required before this vaccine could be recommended for practical application and these studies have begun. Adoption of pig vaccination would be likely to be facilitated if the vaccine were able to be produced in an edible form. A number of aspects of $T$. solium taeniasis/cysticercosis suggest that this parasite may be eradicable (Schantz et al. 1993), and a case can be made for an effective control or eradication strategy based on treatment of Taenia carriers with anthelmintic while at the same time preventing pigs from acting as a source of new infections by application of an effective vaccine (Lightowlers et al. 1999).

One important consideration for control of $T$. solium transmission which may have particular relevance for Asia is the potential involvement of dogs as intermediate hosts for transmission of the parasite to humans. There is an urgent need for scientific investigation of the extent to which this mode of potential transmission of $T$. solium contributes to the epidemiology of the disease.

The medical consequences of infection with $T$. saginata or T. asiatica are substantially less than they are for $T$. solium and hence the urgency for adoption of disease control measures for these parasites are likely to be determined on economic grounds. As mentioned above, a vaccine has been developed which is very effective in preventing $T$. saginata infection in cattle. Given the close relationship between $T$. saginata and $T$. asiatica, the same vaccine may be effective also if used against $T$. asiatica infection in pigs. 


\section{CONCLUSION}

T. solium, T. saginata and T. asiatica are all distributed in Asia. So far all T. solium specimens examined/tested from Asian countries are of the Asian genotype (Nakao et al. 2002). From a medical or public health point of view, $T$. solium cysticercosis has a very serious impact. A greater international focus is being placed on the health significance of neurocysticercosis. Recently, a proposal was presented for neurocysticercosis to become an internationally reportable disease (Roman et al. 2000) and in 2003 the World Health Assembly declared T. solium to be an important target parasite of public health significance worldwide and that it is an eradicable parasitic disease worldwide. The Japanese Government (Ministry of Education) has recommended the establishment of a medical/research network for the control of taeniid cestode zoonoses in Asia and Pacific regions from 2003 for three years. The main purpose of this new project would be to promote transfer of technology for taeniasis/cysticercosis and echinococcosis through collaborative projects. Grants for training at AMC will be available from this fund. Medical, public health, and veterinary staffs who have the responsibilities associated with control of cysticercosis and are interested in such training are invited to contact the senior author.

\section{ACKNOWLEDGMENTS}

This project had financial support from the Japan Society for Promotion of Science (JSPS) and from the Ministry of Education, Japan, to A.I., and from the National Health and Medical Research Council, Australia, to M.W.L.

\section{REFERENCES}

Abuladze, KI. TAENIATA of animals and man and diseases caused by them [Russian]. In: Skrjabin, K.I., ed. Essentials in Cestodology, Volume IV. 1964. Moscow: Academy of Sciences of the USSR. Jerusalem: Israel Program for Scientific Translations, 1970, pp. 40-48.

Allan, JC, Avila, G, Garcia-Noval, J, et al. Immunodiagnosis of taeniasis by coproantigen detection. Parasitology 1990; 101:473-477.
Allan, JC, Verasquez, TM, Garcia, NJ, et al. 1996. Epidemiology of intestinal taeniasis in four rural Guatemalan communities. Ann Trop Med Parasitol 1996;90: 157-165.

Allan, JC, Wilkins PP, Tsang VC, et al. Immunodiagnostic tools for taeniasis. Acta Trop 2003; 87: 87-93.

Bowles, J, McManus, DP. 1994. Genetic characterization of the Asian Taenia, a newly described taeniid cestode of humans. Am J Trop Med Hyg 1994; 50: 33-44.

Brandt, J, Geerts, S, De Deken, R, et al. A monoclonal antibody-based ELISA for the detection of circulating excretory-secretory antigens in Taenia saginata cysticercosis. Int J Parasitol 1992; 22:471-477.

Cai, X, Chai, Z, Jing, Z, et al. 2001. Studies on the development of DNA vaccine against $C y$ sticercus cellulosae infection and its efficacy. SE Asian J Trop Med Public Health 2001; 32:S105-S110.

Chung, JY, Bahk, YY, Huh, S, et al. A recombinant 10-kDa protein of Taenia solium metacestodes specific to active neurocysticercosis. J Infect Dis 1999; 180:1307-1315.

Chung, JY, Yun, DH, Eom, KS, et al. Taenia solium: identification of specific binding regions of metacestode 10kDa protein. Exp Parasitol 2002; 100:87-94.

Cui, J, Wang, ZQ. Outbreaks of human trichinellosis caused by consumption of dog meat in China. Parasite 2001; 8:S74-S77.

Del Brutto, OH, Rajshekhar, V, White, AC, Jr, et al. Proposed diagnostic criteria for neurocysticercosis. Neurology 2001; 57:177-183.

Dissamarn, R, Indrakamhang, P. Trichinosis in Thailand during 1962-1983. Int J Zoonoses 1985; 12:257-266.

Eom, KS, Rim, HJ. Morphologic descriptions of Taenia asiatica sp. n. Korean J Parasitol 1993; 31:1-6.

Eom, KS, Rim, HJ. Epidemiological understanding of Taenia tapeworm infections with special reference to Taenia asiatica in Korea. Korean J Parasitol 2001; 39:267-283.

Eom, KS, Jeon, HK, Kong, Y, et al. Identification of Taenia asiatica in China: molecular, morphological, and epidemiological analysis of a Luzhai isolate. J Parasitol 2002; 88:758-764.

Fan, PC. Taiwan Taenia and taeniasis. Parasitol Today 1988; 4:86-88.

Fan, PC, Chung, WC, Lin, CY, et al. Experimental infection of Thailand Taenia (Chiengmai strain) in domestic animals. Int J Parasitol 1990; 20:121-123.

Fan, PC, Lin, CY, Chung, WC. Experimental infection of Philippine Taenia in domestic animals. Int J Parasitol 1992; 22:235-238.

Fan, PC, Chung, WC, Wu, JC. Experimental infection of an isolate of Taenia solium from Hainan in domestic animals. J. Helminthol 1994; 68:265-266.

Fan, PC, Lin, CY, Chen, CC, et al. Morphological description of Taenia saginata asiatica (Cyclophyllidea: Taeniidae) from man in Asia. J. Helminthol 1995; 69: 299-303.

Fan, PC, Chung, WC. Taenia saginata asiatica: epidemiology, infection, immunological and molecular studies. J Microbiol Immunol Infect 1998; 31:84-89.

Flew, S. Human health, nutrition and heavy metals: report of a survey from the Fly River, western province, 
Papua New Guinea June 1998 [On-line]. Available: www.oktedi.com/reports/reports/31/MWMP_FlyRiver_Health_Report.pdf.

Fritzsche, M, Gottstein, B, Wigglesworth, MC, et al. Serological survey of human cysticercosis in Irianese refugee camps in Papua New Guinea. Acta Trop 1990; 47:69-77.

Garcia, HH, Parkhouse, RM, Gilman, RH, et al. Cysticercosis Working Group in Peru. Serum antigen detection in the diagnosis, treatment, and follow-up of neurocysticercosis patients. Trans R Soc Trop Med Hyg 2000; 94:673-676.

Gauci, CG, Flisser, A, Lightowlers, MW. A Taenia solium oncosphere protein homologous to host-protective Taenia ovis and Taenia saginata $18 \mathrm{kDa}$ antigens. Int J Parasitol 1998; 28:757-760.

Gauci, CG, Lightowlers, MW. Alternative splicing and sequence diversity of transcripts from the oncosphere stage of Taenia solium with homology to the $45 \mathrm{~W}$ antigen of Taenia ovis. Mol Biochem Parasitol 2001; 112:173181.

González, AE, Garcia, HH, Gilman, RH, et al. Effective single-dose treatment or porcine cysticercosis with oxfendazole. Am J Trop Med Hyg 1996; 54:391-394.

González, LM, Montero, E, Harrison, LJS, et al. Differential diagnosis of Taenia saginata and Taenia solium infection by PCR. J Clin Microbiol 2000; 38:737-744.

González, AE, Gavidia, C, Falcon, N, et al. Protection of pigs with cysticercosis from further infection after treatment with oxfendazole. Am J Trop Med Hyg 2001; 65: 15-18.

González LM, Montero E, Puente S, et al. PCR tools for the differential diagnosis of Taenia saginata and Taenia solium taeniasis/cysticercosis from different geographical locations. Diagn Microbiol Infect Dis 2002a; 42: 243-249.

González LM, Montero E, Sciutto E, et al. Differential diagnosis of Taenia saginata and Taenia solium infections: from DNA probes to polymerase chain reaction. Trans R Soc Trop Med Hyg 2002b; 96:S243-S250.

Gottstein, B, Schantz, PM, Tsang, VC. Demonstration of species-specific and cross-reactive components of Taenia solium metacestode antigens. Am J Trop Med Hyg 1986; 35:308-313.

Greene, RM, Hancock, K, Wilkins, PP, et al. Taenia solium: molecular cloning and serological evaluation of 14- and 18-kDa related, diagnostic antigens. J Parasitol 2000; 86: 1001-1007.

Hancock, K, Khan, A, Williams, FB, et al. Characterization of the 8-kilodalton antigens of Taenia solium metacestodes and evaluation of their use in an enzymelinked immunosorbent assay for serodiagnosis. J Clin Microbiol 2003; 41:2577-2586.

Hancock, K, Pattabhi, S, Greene, RM, et al. Characterization and cloning of GP50, a Taenia solium antigen diagnostic for cysticercosis. Mol Biochem Parasitol 2004; 133:115-124.

Harrison, LJ, Joshua, GW, Wright, SH, et al. Specific detection of circulating surface/secreted glycoproteins of viable cysticerci in Taenia saginata cysticercosis. Parasite Immunol 1989; 11:351-370.
Hoberg, EP, Jones, A, Rausch, RL, et al. A phylogenetic hypothesis for species of the genus Taenia (Eucestoda: Taeniidae). J Parasitol 2000; 86:89-98.

Hoberg, EP, Alkire, NL, deQueiroz A. Out of Africa: origins of the Taenia tapeworms in humans. Proc R Soc Lond B Biol Sci 2001; 268:781-787.

Hoberg, EP. Taenia tapeworms: their biology, evolution and socioeconomic significance. Microbes Infect 2002; 4:859-866.

Hou, HW. 1983. Survey of an outbreak of trichinosis caused by eating roast dog meat. Chinese J Prev Med 1983; 17:109-110.

Huerta, M, de Aluja, AS, Fragoso, G, et al. Synthetic peptide vaccine against Taenia solium pig cysticercosis: successful vaccination in a controlled field trial in rural Mexico. Vaccine 2001; 20:262-266.

Ito, A. Cysticercosis in Asian-Pacific Regions. Parasitol Today 1992; 8:182-183.

Ito, A, Craig, PS. Immunodiagnostic and molecular approaches for the detection of taeniid cestode infections. Trends Parasitol 2003; 19:377-381.

Ito, A. Craig, PS. Response to Dorny et al.: Immunodiagnostic approaches for detecting of Taenia solium. Trends Parasitol 2004; (in press) online 17 April 2004.

Ito, A, Chung, WC, Chen, CC, et al. Human Taenia eggs develop into cysticerci in scid mice. Parasitology 1997; 114:85-88.

Ito, A, Ito, M. Human Taenia in severe combined immunodeficiency (SCID) mice. Trends Parasitol 1998; 15: 64-67.

Ito, A, Plancarte, A, Ma, L, et al. 1998. Novel antigens for neurocysticercosis: simple method for preparation and evaluation for serodiagnosis. Am J Trop Med Hyg 1998; 59:291-294.

Ito, A, Plancarte, A, Nakao, M, et al. ELISA and immunoblot using purified glycoproteins for serodiagnosis of cysticercosis in pigs naturally infected with Taenia solium. J Helminthol 1999; 73:363-365.

Ito, A, Nakaya, K, Sako, Y, et al. NOD-scid mouse as an experimental animal model for cysticercosis. SE Asian J Trop Med Publ Health 2001;32:85-89.

Ito, A, Putra, M, Subahar, R, et al. Dogs as alternative intermediate hosts of Taenia solium in Papua (Irian Jaya), Indonesia confirmed by highly specific ELISA and immunoblot using native and recombinant antigens and mitochondrial DNA analysis. J Helminthol 2002a; 76: 311-314.

Ito, A, Nakao, M, Okamoto, M, et al. Mitochondrial DNA of Taenia solium: from basic to applied science. In: Singh, G., Prabhakar, S., eds. Taenia solium Cysticercosis. Oxon: CAB International; 2002b:47-55.

Ito, A, Nakao, M, Wandra, T. Human taeniasis and cysticercosis in Asia. Lancet 2003a; 362:1918-1920.

Ito, A, Yamasaki, H, Nakao, M, et al. Multiple genotypes of Taenia solium-ramifications for diagnosis, treatment and control. Acta Trop 2003b; 87:95-101.

Ito, A, Urbani, C, Qiu, JM, et al. Control of echinococcosis and cysticercosis: a public health challenge to international cooperation in China. Acta Trop 2003c; 86: 3-17. 
Kosin, E, Depary, A, Djohansjah, A. Taeniasis di pulau Samosir. Maj. Kedok. Univ. Sumatra Utara, Medan, 1972; 3:5-11.

Lightowlers, MW. Eradication of Taenia solium cysticercosis: a role for vaccination of pigs. Int J Parasitol 1999; 29:811-817.

Lightowlers, MW, Flisser, A, Gauci, CG, et al. Vaccination against cysticercosis and hydatid disease. Parasitol Today 2000; 16:191-196.

Lightowlers, MW, Colebrook, AL, Gauci, CG, et al. Vaccination against cestode parasites: anti-helminth vaccines that work and why. Vet Parasitol 2003; 115: $83-123$.

Margono, SS, Ito, A, Sato, MO, et al. Taenia solium taeniasis/cysticercosis in Papua, Indonesia in 2001: detection of human worm carriers. J Helminthol 2003; 77: $39-42$.

McCoy, KD. Sympatric speciation in parasites-what is sympatry? Trends Parasitol 2003; 19:400-404.

McManus, DP. Improved diagnosis as an aid to better surveillance of Taenia solium cysticercosis, a potential health threat to Papua New Guinea. Papua New Guinea Med J 1995; 38:287-294.

Meeûs, T, Durand, P, Renaud, F. Species concepts: what for? Trends Parasitol 2003; 19:425-427.

Morgan, JAT, Dejong, RJ, Lwambo, NJS, et al. First report of a natural hybrid between Schistosoma mansoni and $S$. rodhaini. J Parasitol 2003; 89:416-418.

Nakao, M, Okamoto, M, Sako, Y, et al. A phylogenetic hypothesis for the distribution of two genotypes of the pig tapeworm Taenia solium worldwide. Parasitology 2002; 124:657-662.

Nakao, M, Sako, Y, Ito, A. Isolation of polymorphic microsatellite loci from the tapeworm Echinococcus multilocularis. Infect Genet Evol 2003; 3:159-163.

Nguekam, A, Zoli, AP, Condou, L, et al. Kinetics of circulating antigens in pigs experimentally infected with Taenia solium eggs. Vet Parasitol 2003; 111:323-332.

Okamoto, M, Nakao, M, Sako, Y, et al. Molecular variation of Taenia solium in the world. SE Asian J Trop Med Publ Health 2001; 32:90-93.

Parkhouse, RME, Harrison, LJS. Cyst fluid and surface associated glycoprotein antigens of Taenia spp. metacestodes. Parasite Immunol 1987; 9:263-268.

Pawlowski, ZS. Taenia solium: basic biology and transmission. In: Singh, G., Prabhakar, S., eds. Taenia solium Cysticercosis. Oxon: CAB International; 2002:1-13.

Rajshekhar, V, Joshi, DD, Doanh, NQ, et al. Taenia solium taeniasis/cysticercosis in Asia: epidemiology, impact and issues. Acta Trop 2003; 87:53-60.

Roman G, Sotelo J, Del Brutto O, et al. A proposal to declare neurocysticercosis an international reportable disease. Bull WHO 2000; 78:399-406.

Sako, Y, Nakao, M, Ikejima, T, et al. Molecular characterization and diagnostic value of Taenia solium lowmolecular-weight antigen genes. J Clin Microbiol 2000; 38:4439-4444.

Sarti, E, Schantz, PM, Arila, G, et al. Mass treatment against human taeniasis for the control of cysticercosis: a population-based intervention study. Trans $\mathrm{R}$ Soc Trop Med Hyg 2000; 94:85-89.
Sato, MO, Yamasaki, H, Sako, Y, et al. Evaluation of tongue inspection and serology for diagnosis of Taenia solium cysticercosis in swine: usefulness of ELISA using purified glycoproteins and recombinant antigen. Vet Parasitol 2003; 111:309-322.

Schantz PM, Cruz M, Sarti E, et al. Potential eradicability of taeniasis and cysticercosis. Bull Pan Am Health Organ 1993; 27:397-403.

Simanjuntak GM, Margono SS, Schlan R, et al. An investigation on taeniasis and cysticercosis in Bali. SE Asian J Trop Med Public Health 1977; 8:494-497.

Simanjuntak, G, Margono, SS, Okamoto, M, et al. Taeniasis/cysticercosis in Indonesia as an emerging disease. Parasitol Today 1997; 13:321-323.

Singh, G, Prabhakar, S, Ito, A, et al. Taenia solium taeniasis and cysticercosis in Asia. In: Singh, G., Prabhakar, S., eds. Taenia solium Cysticercosis. Oxon: CAB International; 2002:111-127.

Subahar, R, Hamid, A, Purba, W, et al. Taenia solium infection in Irian Jaya (West Papua), Indonesia: a pilot serological survey of human and porcine cysticercosis in Jayawijaya District. Trans R Soc Trop Med Hyg 2001; 95:388-390.

Suroso, T. Petunjuk pemberantasan taeniasis/sistiserkosis di Indonesia. Depkes RI, Ditjen Jakarta. PPM \& PL; 2000:1-30.

Sutisna, IP, Fraser, A, Kapti, IN, et al. Community prevalence study of taeniasis and cysticercosis in Bali, Indonesia. Trop Med Int Health 1999; 4:288-294.

Thompson, RCA, Owen, IL, Puana, I, et al. Parasites and biosecurity - the example of Australia. Trends Parasitol 2003; 19:410-416.

Tsang, VC, Brand, JA, Boyer, AE. An enzyme-linked immunoelectrotransfer blot assay and glycoprotein antigens for diagnosing human cysticercosis (Taenia solium). J Infect Dis 1989; 159:50-59.

Tsang, VC, Pilcher, JA, Zhou, W, et al. Efficacy of the immunoblot assay for cysticercosis in pigs and modulated expression of distinct IgM/IgG activities to Taenia solium antigens in experimental infections. Vet Immunol Immunopathol 1991; 29:69-78.

Yamasaki, H, Nakao, M, Sako, Y, et al. DNA differential diagnosis of human taeniid cestodes by base excision sequence scanning thymine-base reader analysis with mitochondrial genes. J Clin Microbiol 2002; 40:38183821.

Yamasaki, H, Allan, JC, Sato, MO, et al. DNA differential diagnosis of taeniasis/cysticercosis by multiplex PCR. J Clin Microbiol 2004; 42:548-553.

Yang, HJ, Chung, JY, Yun, DH, et al. Immunoblot analysis of a $10 \mathrm{kDa}$ antigen in cyst fluid of Taenia solium metacestodes. Parasite Immunol 1998; 20:483-488.

Wandra, T, Subahar, R, Simanjuntak, GM, et al. Resurgence of cases of epileptic seizures and burns associated with cysticercosis in Assologaima, Jayawijaya, Irian Jaya, Indonesia, 1991-95. Trans R Soc Trop Med Hyg 2000; 94:46-50.

Wandra, T, Ito, A, Yamasaki, H, et al. Taenia solium cysticercosis, Irian Jaya, Indonesia. Emerging Infect Dis 2003; 9:884-885.

Wang, $\mathrm{QM}$, Sun, $\mathrm{SH}, \mathrm{Hu}, \mathrm{ZL}$, et al. Immune response and 
protection elicited by DNA immunization against Taenia cysticercosis. Vaccine 2003; 21:1672-1680.

Wilkins, PP, Allan, JC, Verastegui, M, et al. Development of a serologic assay to detect Taenia solium taeniasis. Am J Trop Med Hyg 1999; 60:199-204.

Willingham, AL, De, NV, Doanh, NQ, et al. Current status of cysticercosis in Vietnam. SE Asian J Trop Med Public Health 2003; 34:35-50.

Zarlenga, DS, McManus, DP, Fan, PC, et al. Characterization and detection of a newly described Asian taeniid using cloned ribosomal DNA fragments and sequence amplification by the polymerase chain reaction. Exp Parasitol 1991; 72:174-183.

Address reprint requests to: Dr. Akira Ito Department of Parasitology Asahikawa Medical College Asahikawa 078-8510, Japan

E-mail: akiraito@asahikawa-med.ac.jp 